\title{
BIODIESEL EM TRATOR AGRÍCOLA: COMPORTAMENTO OPERACIONAL EM FUNÇÃO DO TIPO E PROPORÇÕES DE MISTURA NO DIESEL DE PETRÓLEO
}

\author{
Leomar Paulo de Lima ${ }^{1}$, Afonso Lopes ${ }^{2}$, Melina Cais Jejcic Oliveira ${ }^{3}$, Murilo Coelho Teodoro Neves ${ }^{4}$, Priscila \\ Sawasaki Iamaguti $^{5}$
}

\begin{abstract}
RESUMO
O biodiesel pode ser obtido a partir de óleos vegetais, gorduras animais ou óleos residuais por meio da reação com etanol ou metanol e destaca-se entre as fontes renováveis de energia apontadas como solução para aumentar a segurança no suprimento de energia e minimizar alguns problemas ambientais decorrentes do uso de combustíveis derivados do petróleo. Este trabalho teve o objetivo de avaliar o consumo de combustível e a opacidade da fumaça do trator agrícola em função do tipo e proporções de mistura de biodiesel com diesel comum de petróleo. O experimento foi realizado no Departamento de Engenharia Rural da FCAV-UNESP, Jaboticabal-SP, utilizando-se um trator 4x2 TDA de 80,9 $\mathrm{kW}(110 \mathrm{cv})$ de potência no motor. O delineamento experimental foi inteiramente casualizado em esquema fatorial 6x2, em que as combinações dos fatores foram seis proporções de mistura biodiesel/diesel (B0, B5, B25, B50, B75 e B100, em que o número indica a percentagem de biodiesel no diesel) e dois tipos de biodiesel (dendê e mamona). Foram realizadas as seguintes avaliações: consumo horário volumétrico $\left(\mathrm{L} \mathrm{h}^{-1}\right)$, consumo horário ponderal $\left(\mathrm{kg} \mathrm{h}^{-1}\right)$, consumo específico de combustível $\left(\mathrm{g} \mathrm{kW}^{-1} \mathrm{~h}^{-1}\right)$ e opacidade da fumaça. Os resultados evidenciaram que a partir do uso da mistura com $50 \%$ de biodiesel ocorreu aumento no consumo específico, entretanto o tipo de biodiesel não influenciou a referida variável. A opacidade da fumaça reduziu a partir da adição de $5 \%$ de biodiesel, destacando que o tipo de biodiesel também influenciou esta medida, sendo o dendê de menor opacidade.
\end{abstract}

Palavras-chave: biocombustível, consumo específico, opacidade da fumaça.

\section{ABSTRACT \\ BIODIESEL IN AN AGRICULTURAL TRACTOR: OPERATIONAL BEHAVIOR AS A FUNCTION OF THE TYPE AND PROPORTIONS BLENDED IN DIESEL FUEL}

Biodiesel can be obtained from reacting vegetable oils, animal fats or waste oil with ethanol or methanol and stands out among renewable energy sources identified as solutions to increase energy supply security and minimize potential environmental problems arising from the use of petroleum-based fuels. The aim of this study was to evaluate the consumption of fuel and opacity of smoke from farm tractors in function of the type and proportions of biodiesel blended with common diesel oil. The experiment was conducted at the Department of Agricultural Engineering, FCAVUNESP, Jaboticabal-SP, using a 4x2 TDA tractor with engine power of $80.9 \mathrm{~kW}(108 \mathrm{hp})$. The experimental design was completely randomized in a $6 \times 3$ factorial, in which the factors consisted of six proportions of biodiesel/diesel blending (B0, B5, B25, B50, B75 and B100, in which the number indicates the percentage of biodiesel blended in diesel) and two types of biodiesel (palm and castor bean). The following parameters were determined: hourly volumetric consumption (L $\left.\mathrm{h}^{-1}\right)$, hourly weight consumption $\left(\mathrm{kg} \mathrm{h}^{-1}\right)$, specific fuel consumption $\left(\mathrm{g} \mathrm{kW}^{-1} \mathrm{~h}^{-1}\right)$ and smoke opacity. The results showed that biodiesel blends at or greater than the 50\% resulted in increased specific consumption, however the type of biodiesel did not affect this variable. Smoke opacity was reduced for biodiesel blends of 5\% or greater, indicating that the biodiesel type also influenced this measure, where palm oil based biodiesel presented lower opacity.

Keywords: biofuel, specific consumption, smoke opacity

\section{Recebido para publicação em 15/12/2012. Aprovado em 02/08/2013.}

1 - Professor (Licenciatura em Ciências Agrárias), Doutor em Agronomia, IFTM, Uberlândia-MG, leomar@iftm.edu.br

2 - Eng. Agrícola, Professor Adjunto, Depto. de Engenharia Rural, DER/FCAV-UNESP, Jaboticabal (SP), afonso@fcav.unesp.br

3 - Engenheira Agrônoma, Doutoranda em Agronomia, DER/FCAV-UNESP, Jaboticabal (SP), melina_cais@yahoo.com.br

4 - Engenheiro Agrônomo, Doutorando em Agronomia, DER/FCAV-UNESP, Jaboticabal (SP), murilocoelho.tn@gmail.com

5 - Engenheira Agrônoma, Mestranda em Agronomia, DER/FCAV-UNESP, Jaboticabal (SP), priiamaguti@hotmail.com 


\section{INTRODUÇ̃̃O}

Biodiesel é um biocombustível renovável e produzido a partir de óleo vegetal e álcool anidro na presença de catalisador. Esse produto é indicado para motores de ignição por compressão, podendo ser utilizado como aditivo ou em substituição ao diesel de petróleo (LOPES et al., 2007). Dependendo do processo de produção, o biodiesel pode ser filtrado ou destilado, metílico ou etílico, produzido com óleo degomado ou residual.

O biodiesel produzido no Brasil, independentemente da matéria-prima, deve atender alguns parâmetros físicos e químicos que assegurem sua qualidade (DABDOUB et al., 2009). As propriedades do biodiesel são fortemente influenciadas pelas características individuais dos ésteres graxos que formam esse combustível. Ésteres de ácidos graxos saturados e/ou hidroxilados, como no biodiesel de mamona, apresentam alta densidade e viscosidade. Enquanto os ésteres de ácidos graxos insaturados, como os que compõem o biodiesel de soja são menos viscosos (LÔBO et al., 2009).

A Agência Nacional de Petróleo, Gás Natural, e Biocombustível, desde março de 2008, passou a não recomendar o uso do óleo de mamona, tido como promissor, para se produzir biodiesel. A alta viscosidade do biodiesel de mamona é prejudicial para os motores a diesel, tornando-o inadequado para ser utilizado nos tanques. Somente como mistura ao diesel fóssil ou a outro biodiesel menos viscoso, se enquadrará as exigências da especificação da ANP $\left(3,0-6,0 \mathrm{~mm}^{2}\right.$ $\mathrm{s}^{-1}$ ) (MENEGHETTI et al., 2007; TEIXEIRA et al., 2010) o que motivou o presente trabalho.

Segundo Soranso et al. (2008) a principal vantagem técnica trazida pelo biodiesel é a adaptabilidade aos atuais motores de combustão interna de ciclo diesel. Enquanto o uso de outros combustíveis como o gás natural ou biogás requer prévia adaptação dos motores, o uso de biodiesel é feito de forma satisfatória, sem precisar de qualquer alteração de ordem técnica no propulsor. Por isso, não há registro de prejuízo na eficiência térmica, $o$ que o configura como alternativa capaz de atender a frota já existente no setor de transportes brasileiro.

Castellanelli et al. (2008) compararam o desempenho do motor de ignição por compressão da marca CUMMINS, modelo 4BTA 3.9, utilizando misturas de biodiesel etílico de óleo de soja no diesel. Ao comparar, primeiramente o diesel (B0 - testemunha) e biodiesel (B100), foi observado que o motor apresentou desempenho inferior nos quesitos potência, torque e consumo específico, quando se utilizou B100. O B20 destacou-se apresentando desempenho superior ao do diesel. Na sequencia da análise, à medida que se aumentou a porcentagem de biodiesel no diesel, houve menor desempenho, sendo o B100 considerado a pior opção. As misturas B2, B5 e B10 mostraram desempenho semelhante ao do diesel. Estas diferenças para as grandes proporções se devem à inferioridade do biodiesel em relação ao diesel na propriedade poder calorífico.

Vários trabalhos tem sido realizados sobre as propriedades do biodiesel e de suas emissões (ZHU, 2010). A substituição de diesel por misturas com biodiesel e as plantações de oleaginosas, como dendê e babaçu, permitem ao País obter créditos de carbono, sob o Mecanismo de Desenvolvimento Limpo (MDL). Estudos mostram que a cultura do dendê é capaz de capturar 36 toneladas de $\mathrm{CO}_{2}$ da atmosfera por hectare cultivado, enquanto a capacidade do pinus é de 5 toneladas de $\mathrm{CO}_{2}$ por hectare (BELMIRO et al., 2007).

Pressupõe-se que o diesel com maiores porcentagens de mistura com biodiesel aumentem o consumo de combustível e reduzam a opacidade da fumaça, e que os diferentes tipos de biodiesel mantenham estável o funcionamento do motor do trator agrícola. Este trabalho teve o objetivo de avaliar o consumo de combustível e a opacidade da fumaça de trator agrícola em função dos tipos e proporções de mistura de biodiesel com diesel comum de petróleo.

\section{MATERIAL E MÉTODOS}

O trabalho foi conduzido em área do Laboratório de Máquinas e Mecanização Agrícola - LAMMA, do Departamento de Engenharia Rural, da Universidade Estadual Paulista - UNESP, Campus de Jaboticabal-SP. Possui localização geodésica definida pelas coordenadas $21^{\circ} 15^{\text {' }}$ latitude sul e $48^{\circ} 18^{\prime}$ longitude oeste, com altitude 
média de $570 \mathrm{~m}$. A região apresenta temperatura média anual de $22,2{ }^{\circ} \mathrm{C}$, precipitação média anual de $1.425 \mathrm{~mm}$, umidade relativa média de $71 \%$ e pressão atmosférica de 94,3 kPa. O clima da região, segundo a classificação de Köppen, é do tipo Aw, definido como tropical úmido.

O solo da área experimental foi classificado como Latossolo Vermelho Eutroférrico típico, com relevo suave ondulado e declividade média de $3 \%$, conforme o Sistema Brasileiro de Classificação de Solos (ANDREOLI \& CENTURION, 1999). $\mathrm{O}$ teor médio de água no dia do ensaio, no perfil de $0-15$ e $15-30 \mathrm{~cm}$ de profundidade, foram 11,2 e $13,4 \%$, respectivamente segundo o método gravimétrico-padrão. A análise granulométrica da camada de 0-20 cm para argila, silte, areia fina e areia grossa foi $51 ; 29 ; 10$ e $10 \%$, respectivamente, sendo o mesmo classificado como textura argilosa.

Os produtos utilizados como biodiesel foi do tipo dendê (Elaeis guianeensis) e mamona (Ricinus communis L.). O processo de produção e o fornecimento dos biocombustíveis ficaram a cargo do Laboratório de Desenvolvimento de Tecnologias Limpas - LADETEL, da Universidade de São Paulo - USP, Campus de Ribeirão Preto-SP.

O experimento foi realizado na condição dinâmica, para avaliar o desempenho do trator, e na condição estática, para avaliar a opacidade da fumaça.

$\mathrm{O}$ ensaio de desempenho teve delineamento experimental inteiramente casualizado, em esquema fatorial $2 \times 6$, com quatro repetições, totalizando 48 observações. As combinações dos fatores foram dois tipos de biodiesel (dendê e mamona) e seis proporções de mistura diesel/ Biodiesel (B0, B5, B25, B50, B75 e B100). Cada parcela experimental possuía $30 \mathrm{~m}$ de comprimento e, entre si, na direção longitudinal, foi reservado espaço de $15 \mathrm{~m}$ destinado à realização de manobras, tráfego de máquinas e estabilização do conjunto motomecanizado em cada tratamento.

No ensaio de opacidade, foi utilizado o delineamento inteiramente casualizado, em esquema fatorial $6 \times 2$, com três repetições, totalizando 36 observações. As combinações dos fatores foram dois tipos de biodiesel (dendê e mamona) e seis proporções de mistura diesel/ biodiesel (B0, B5, B25; B50; B75 e B100).

Para o ensaio de desempenho, foi utilizado um trator Valtra, modelo BM 110, 4x2 TDA, com potência de $80,9 \mathrm{~kW}(110 \mathrm{cv})$ no motor, a 2.300 rpm, massa total de $6.160 \mathrm{~kg}$, ressaltando-se que, durante os ensaios, o trator trabalhou na rotação de $2.000 \mathrm{rpm}$, sendo que a velocidade média de trabalho conseguida foi de $5,3 \mathrm{~km} \mathrm{~h}^{-1}$ com a combinação do câmbio $3^{\mathrm{a}} \mathrm{L}$. O trator encontravase instrumentado com célula de carga, medidor de rotação da tomada de potência (TDP), medidor de rotação dos rodados, unidade de radar e medidor de temperatura e do fluxo de combustível da entrada e do retorno da bomba injetora. Toda a instrumentação foi ligada a um sistema de aquisição de dados, descrita conforme Lopes (2006).

Com a finalidade de definir a carga correspondente ao esforço máximo, tecnicamente viável, que o trator de teste poderia tracionar na barra de tração, foi utilizado um escarificador Marchesan, modelo AST/MATIC 7, regulado com cinco hastes, com espaçamento de $45 \mathrm{~cm}$, ponteira sem asa com $8 \mathrm{~cm}$ de largura, equipado com rolo destorroador e discos de corte de palha. A operação foi realizada com a haste do escarificador na profundidade de trabalho de $28 \mathrm{~cm}$, sendo a área manejada no sistema de plantio direto, obtendo-se um resultado de aproximadamente $25 \mathrm{kN}$.

Devido à grande variabilidade da resistência do solo para a avaliação do consumo de combustível, e depois de conhecida a força na barra de tração requerida pelo escarificador, esse foi substituído por um segundo trator Valtra, modelo BH140, 4x2 TDA, com potência de $103 \mathrm{~kW}(140 \mathrm{cv})$ a $2.400 \mathrm{rpm}$ no motor, massa total de $7.600 \mathrm{~kg}$, denominado trator de frenagem, acoplado ao trator de teste por meio de um cabo de aço, formando um comboio. $\mathrm{O}$ trator de frenagem foi utilizado desligado e engrenado, pois a única função era oferecer carga na barra de tração do trator teste o mais uniforme possível, sendo que a velocidade média de trabalho conseguida foi de $5,3 \mathrm{~km} \mathrm{~h}^{-1}$ com a combinação do câmbio $4^{\mathrm{a}} \mathrm{L}$ e a patinagem média dos rodados de $8,6 \%$.

O sistema de medição de combustível consiste em dois conjuntos de sensores, um para a alimentação e o outro para o retorno da bomba injetora. Cada conjunto contém um medidor de fluxo da marca Oval Corporation, modelo Flowmate LSN 48, com precisão de $1 \%$ sobre a vazão nominal e vazão máxima de $100 \mathrm{~L} \mathrm{~h}^{-1}$, e um sensor de temperatura do tipo resistivo, modelo PT 100 (resistência de 100 ohms a $0{ }^{\circ} \mathrm{C}$ ), com faixa de medida de $-200{ }^{\circ} \mathrm{C}$ a $800^{\circ} \mathrm{C}$. Os valores de vazão de combustível foram obtidos em $\mathrm{mL} \mathrm{s}^{-1}$, e de temperatura em ${ }^{\circ} \mathrm{C}$. 
O consumo de combustível foi medido em cada parcela, obtendo-se o volume e a temperatura do combustível que alimenta a bomba injetora, e o volume e a temperatura do combustível que retorna ao tanque, sendo o combustível consumido dado pela diferença entre as duas medidas. A temperatura do combustível medida foi utilizada para a correção da densidade do combustível.

Com base no volume consumido e no tempo de percurso em cada parcela, foi determinado o consumo horário volumétrico, conforme a Equação 1:

$\operatorname{Chv}=\left(\frac{\mathrm{Va}-\mathrm{Vr}}{\mathrm{t}}\right) 3,6$

em que,

Chv $=$ consumo horário volumétrico, $\mathrm{L} \mathrm{h}^{-1}$;

$\mathrm{Va}=$ volume do combustível de alimentação, $\mathrm{mL}$;

$\mathrm{Vr}=$ volume do combustível de retorno, $\mathrm{mL}$;

$\mathrm{t}=$ tempo de percurso na parcela, $\mathrm{s}$, e

$3,6=$ fator de conversão;

Para a obtenção do consumo horário ponderal expresso em massa, foi necessário determinar a densidade em função da temperatura nas seis proporções de mistura. A temperatura do combustível foi monitorada nos mesmos pontos onde foram realizadas as medidas de fluxo. A densidade foi determinada no intervalo de temperatura de 10 a $70{ }^{\circ} \mathrm{C}$, em passos de 5 e 5 ${ }^{\circ} \mathrm{C}$, pela análise de regressão, obtida por meio de análise estatística.

Para calcular o consumo horário ponderal, considerou-se a influência da densidade do combustível de alimentação e de retorno no momento do teste, conforme Equação 2:

$$
\text { Chp }=\frac{(\text { Va } * \text { Dca }-V r * D c r)}{t} 0,0036
$$

em que,

Chp = consumo horário ponderal, $\mathrm{kg} \mathrm{h}^{-1}$;

$\mathrm{Va}=$ volume do combustível de alimentação, $\mathrm{mL}$;

$\mathrm{Dca}=$ densidade do combustível de alimentação, $\mathrm{g} \mathrm{L}^{-1}$;

$\mathrm{Vr}=$ volume do combustível de retorno, $\mathrm{mL}$;

$\mathrm{Dcr}=$ densidade do combustível de retorno, $\mathrm{g} \mathrm{L}^{-1}$;

$\mathrm{t}=$ tempo de percurso na parcela, $\mathrm{s}, \mathrm{e}$

$0,0036=$ fator de conversão;
O consumo específico é o consumo de combustível expresso em unidade de massa por unidade de potência requerida na barra de tração, conforme equação (3):

$\mathrm{Ce}=\left(\frac{\mathrm{Chp}}{\mathrm{PB}}\right) 1000$

em que,

$\mathrm{Ce}=$ consumo específico, $\mathrm{g} \mathrm{kW}^{-1} \mathrm{~h}^{-1}$;

$\mathrm{Chp}=$ consumo horário ponderal, $\mathrm{kg} \mathrm{h}^{-1}$;

$\mathrm{PB}=$ potência na barra de tração, $\mathrm{kW}, \mathrm{e}$

$1000=$ fator de conversão;

Os ensaios referentes à opacidade da fumaça do cano de escape do trator foram realizados de acordo com o método da aceleração livre, que é o regime em que o motor é submetido ao máximo débito de combustível, conforme NBR 13037 (ABNT, 2001). As medições de opacidade são feitas em $K$, que é o coeficiente de absorção de luz, e tem como unidade $\mathrm{m}^{-1}$ (TECNOMOTOR, 2010).

Os dados foram tabulados e submetidos à análise de variância e ao teste de comparação de médias de Tukey, a $5 \%$ de probabilidade, conforme recomendação de Banzatto \& Kronka (2006). Para a opacidade da fumaça e consumo específico de combustível foi estudado modelo de ajuste de regressão que melhor explicasse o comportamento dessas variáveis, em função da proporção de biodiesel. Para o caso da densidade, ajustou-se um modelo de superfície de resposta que também explicasse essa variável em função da temperatura e da proporção de biodiesel.

Neste trabalho, utilizou-se da análise de variância (teste $\mathrm{F}$ ) para selecionar o modelo de equação de maior expoente significativo.

\section{RESULTADOS E DISCUSSÃO}

No Quadro 1 encontram-se apresentados a síntese da análise de variância e o teste de médias para as variáveis consumo horário volumétrico, consumo horário ponderal, consumo específico de

\section{REVENG}


BIODIESEL EM TRATOR AGRÍCOLA: COMPORTAMENTO OPERACIONAL EM FUNÇÃO DO TIPO...

Quadro 1. Síntese da análise de variância e teste de médias para as variáveis: consumo horário volumétrico (Chv), consumo horário ponderal (Chp), consumo específico (Cesp) e opacidade da fumaça.

\begin{tabular}{ccccc}
\hline Fatores & $\begin{array}{c}\text { Chv } \\
\mathrm{L} \mathrm{h}^{-1}\end{array}$ & $\begin{array}{c}\text { Chp } \\
\mathrm{kg} \mathrm{h}^{-1}\end{array}$ & $\begin{array}{c}\text { Cesp } \\
\mathrm{g} \mathrm{kW}^{-1} \mathrm{~h}^{-1}\end{array}$ & $\begin{array}{c}\text { Opacidade } \\
\mathrm{m}^{-1}\end{array}$ \\
\hline Tipo de Biodiesel (TB) & & & & \\
Dendê & $14,19 \mathrm{a}$ & $12,29 \mathrm{a}$ & $367,28 \mathrm{a}$ & $1,38 \mathrm{a}$ \\
Mamona & $14,21 \mathrm{a}$ & $12,29 \mathrm{a}$ & $366,96 \mathrm{a}$ & $1,42 \mathrm{~b}$ \\
\hline Proporção de Biodiesel (Bn) & & & & \\
B0 & $12,79 \mathrm{a}$ & $10,83 \mathrm{a}$ & $329,36 \mathrm{a}$ & $1,72 \mathrm{a}$ \\
B5 & $13,48 \mathrm{ab}$ & $11,42 \mathrm{~b}$ & $338,17 \mathrm{a}$ & $1,67 \mathrm{~b}$ \\
B25 & $13,16 \mathrm{~b}$ & $11,30 \mathrm{ab}$ & $332,59 \mathrm{a}$ & $1,39 \mathrm{c}$ \\
B50 & $14,61 \mathrm{c}$ & $12,63 \mathrm{c}$ & $377,66 \mathrm{~b}$ & $1,31 \mathrm{~d}$ \\
B75 & $15,58 \mathrm{~d}$ & $13,67 \mathrm{~d}$ & $408,81 \mathrm{c}$ & $1,21 \mathrm{e}$ \\
B100 & $15,58 \mathrm{~d}$ & $13,91 \mathrm{~d}$ & $416,12 \mathrm{c}$ & $1,10 \mathrm{f}$ \\
\hline TESTE F & & & \\
TB & $0,443^{\mathrm{NS}}$ & $0,0033^{\mathrm{NS}}$ & $0,0079^{\mathrm{NS}}$ & $46,6883^{* *}$ \\
B & $84,9525^{* *}$ & $128,7325^{* *}$ & $76,3219^{* *}$ & $1006,5679^{* *}$ \\
TBxB & $1,4526^{\mathrm{NS}}$ & $2,1792^{\mathrm{NS}}$ & $1,7554^{\mathrm{NS}}$ & $17,5322^{* *}$ \\
\hline MEDIA & 14,20 & 12,29 & 367,12 & 1,40 \\
\hline C.V.\% & 2,65 & 2,64 & 3,46 & 2,71 \\
\hline
\end{tabular}

Médias seguidas pela mesma letra minúscula na coluna, não diferem entre si pelo teste de Tukey a $5 \%$ de probabilidade. **: significativo $(\mathrm{P}<0,01)$; *: significativo $(\mathrm{P}<0,05)$; NS: não significativo; C.V.: coeficiente de variação.

combustível e opacidade da fumaça em função do tipo e proporções de mistura de biodiesel com diesel.

$\mathrm{O}$ tipo de biodiesel não influenciou significativamente no consumo volumétrico de combustível. Porém em relação à proporção de biodiesel, ao comparar B0 e B100, o consumo aumentou $21,81 \%$. No entanto, esses resultados estão próximos aos encontrados por Tabile et al. (2009) e Murugesan et al. (2009), que afirmam esse aumento ser em função do menor poder calorífico do biodiesel em relação ao diesel, sendo necessário queimar mais combustível para realizar a mesma quantidade de trabalho, ressaltando-se que o consumo volumétrico é a informação mais utilizada no meio dos agricultores.

O consumo ponderal teve comportamento semelhante ao volumétrico. A relevância dessa medida é para os profissionais que trabalham na distribuição dos combustíveis, com a quantidade de massa que sai da origem sendo a mesma que chega ao seu destino. Ademais, serve também para acompanhar a qualidade do produto que se considera a densidade.

$O$ fator tipo de biodiesel não influenciou significativamente no consumo específico de combustível. Com relação às proporções de mistura de biodiesel no diesel, nota-se que a partir de B50, B75 e B100 influenciaram significativamente na variável. Todavia, comparando B0 a B100, o consumo específico aumentou $26,34 \%$. Esse aumento se deve ao menor poder calorífico do biodiesel em relação ao diesel. Diferentes valores para a variação do consumo específico de combustível são observados por outros autores (CASTELLANELLI et al., 2008 e CORRÊA et al., 2008). O consumo específico é a forma mais utilizada no meio científico para comparar tratamentos, pois leva em consideração 


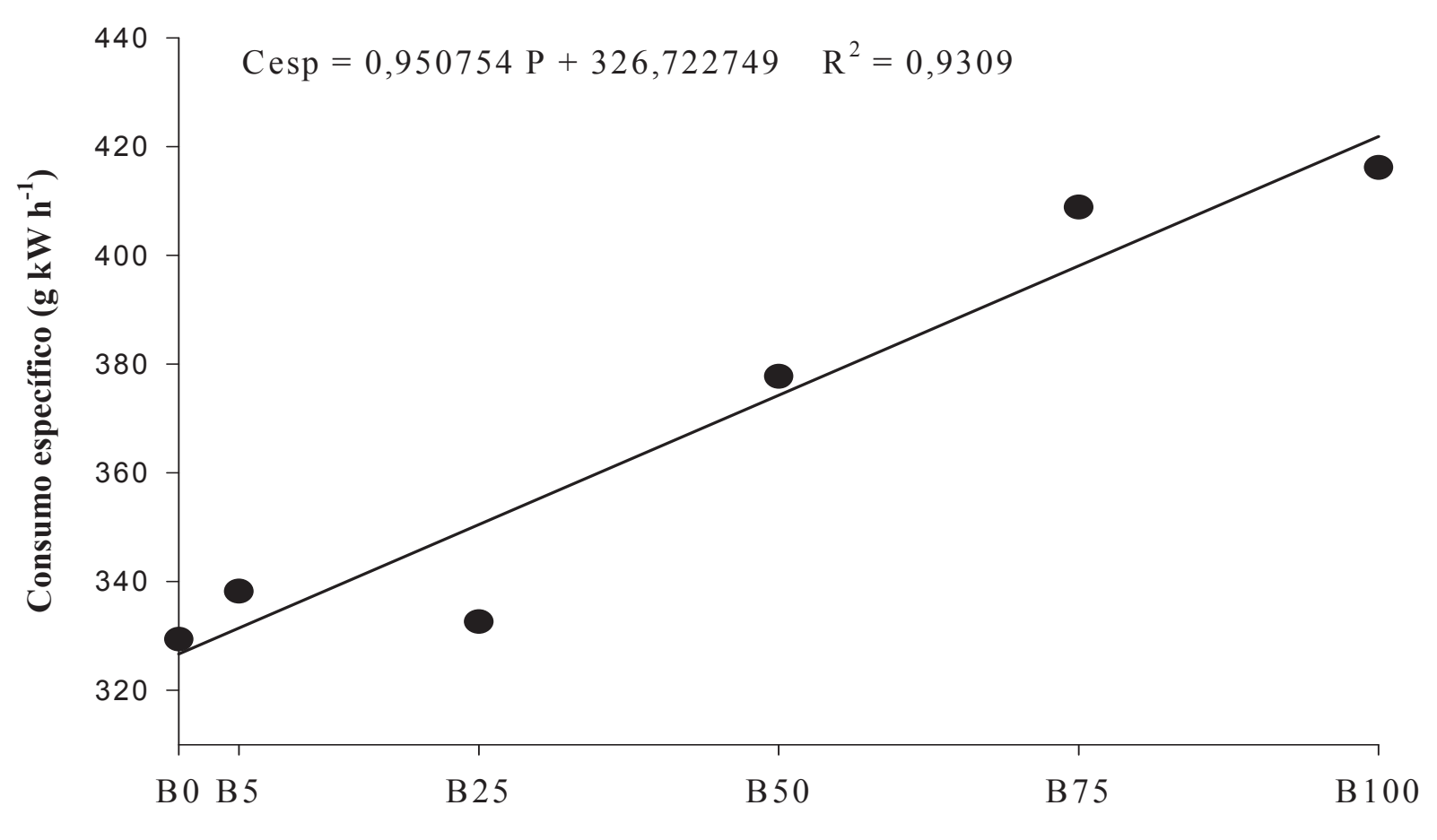

Proporção de mistura (\%)

Figura 1. Modelo de regressão para consumo específico em função da proporção de mistura de biodiesel de dendê e mamona com diesel.

a quantidade de combustível consumida, potência desenvolvida e densidade do produto.

O comportamento do consumo específico em função da proporção de mistura teve comportamento linear, conforme se nota na Figura 1.

Para a variável opacidade da fumaça observa-se que a interação entre os fatores tipo e proporção de biodiesel foi significativa. Analisando-se o fator tipo de biodiesel (Quadro 2), verifica-se que a opacidade da fumaça reduziu à medida que aumentou a quantidade de biodiesel na mistura, destacando-se o biodiesel de dendê em $36,25 \%$ e mamona em $35,26 \%$, respectivamente. Estes resultados reforçam os relatos de que as propriedades do biodiesel são fortemente influenciadas pelas características individuais dos ésteres graxos que formam esse combustível. Outra propriedade que pode influenciar nas emissões do motor é o número de cetano, podendo variar muito entre os diferentes tipos de biodiesel, comportamento também observado em trabalho realizado por Tabile et al. (2009).
Analisando-se a variável proporção observa-se no Quadro 2, que o biodiesel de dendê apresentou significativamente menor opacidade em relação ao biodiesel de mamona exceto para as proporções B0, B5 e B25 que não apresentaram diferença estatística para a variável. A redução na opacidade é devido à menor emissão de material particulado pelo uso do biodiesel, conforme foi observado por Mazziero et al. (2006), que avaliaram em bancada dinamométrica os níveis de emissões de gases em motor de combustão por compressão, alimentado com éster etílico de girassol, verificando uma redução de $41 \%$ nas emissões de material particulado (MP).

Os níveis de opacidade (Quadro 2) são comparados a resolução CONAMA nº 251 de 1999 (CONAMA, 1999) e verifica-se que, neste caso, o trator estaria aprovado caso fosse aplicado o teste de emissão, pois está abaixo de $2,8 \mathrm{~m}^{-1}$.

O comportamento da opacidade da fumaça em função da proporção de mistura para os três tipos de biodiesel teve comportamento linear, conforme se nota na Figura 2.

\section{REVENG 447-455p.}


Quadro 2. Síntese do desdobramento da interação tipo e proporção de biodiesel para a variável opacidade da fumaça $\left(\mathrm{m}^{-1}\right)$.

\begin{tabular}{lcccccc}
\hline Tipo de Biodiesel & \multicolumn{7}{c}{ Proporção de biodiesel } \\
\hline \multirow{2}{*}{ Dendê } & B0 & B5 & B25 & B50 & B75 & B100 \\
Mamona & $1,71 \mathrm{Aa}$ & $1,67 \mathrm{Aa}$ & $1,40 \mathrm{Ab}$ & $1,23 \mathrm{Bc}$ & $1,19 \mathrm{Bd}$ & $1,09 \mathrm{Be}$ \\
& $1,73 \mathrm{Aa}$ & $1,67 \mathrm{Ab}$ & $1,38 \mathrm{Ac}$ & $1,40 \mathrm{Ac}$ & $1,24 \mathrm{Ad}$ & $1,12 \mathrm{Ae}$ \\
\hline
\end{tabular}

Médias seguidas de mesma letra maiúscula na coluna e minúscula na linha não deferem entre si, pelo teste de Tukey a $5 \%$ de probabilidade.

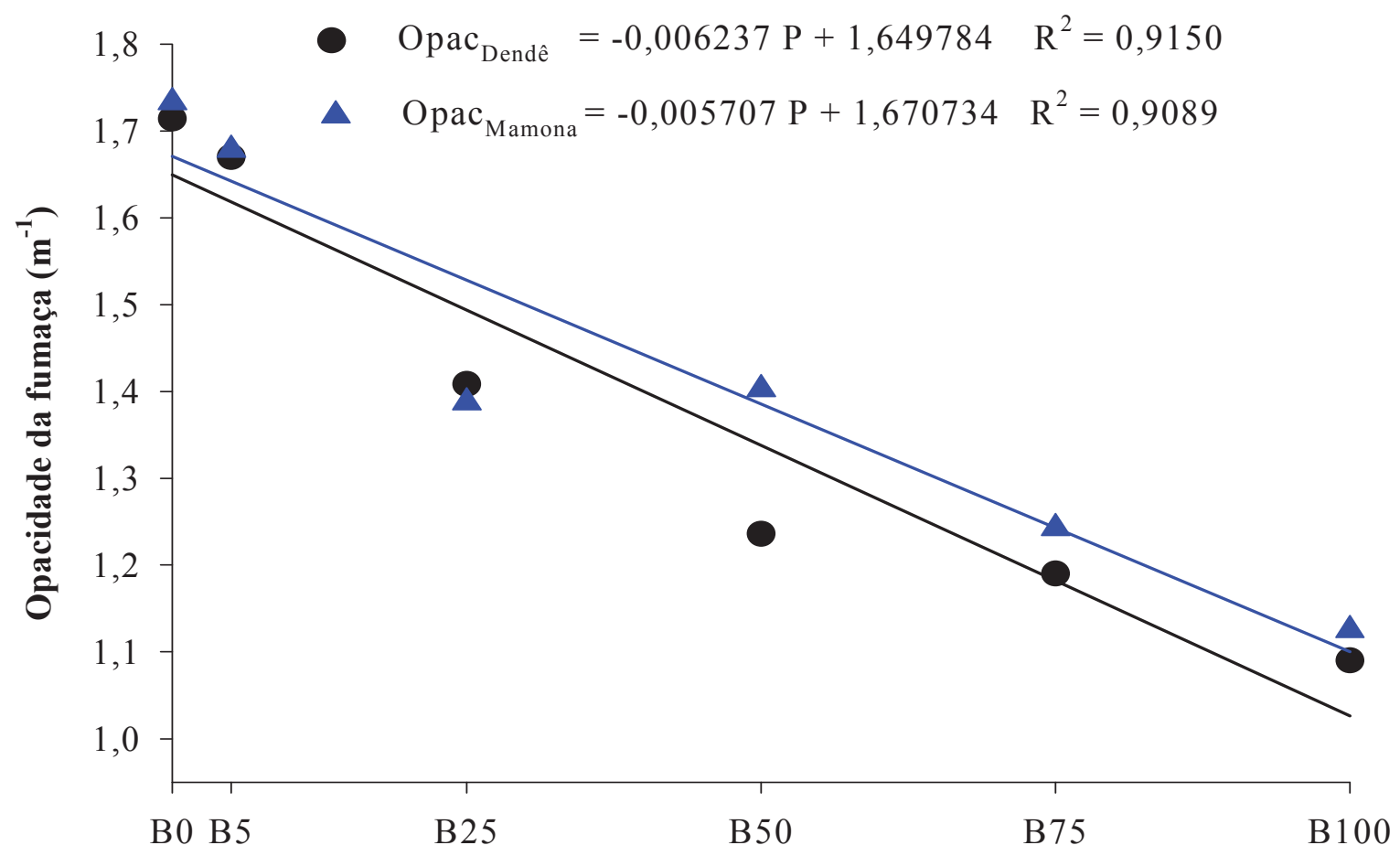

Proporção de mistura (\%)

Figura 2. Modelo de regressão para opacidade da fumaça em função da proporção de mistura de biodiesel de dendê e mamona com diesel.

\section{CONCLUSÕES}

Com base nos resultados obtidos, pode-se concluir que, para as condições de ensaio realizadas:

- O incremento de biodiesel a partir de $50 \%$ aumenta significativamente o consumo específico de combustível do trator;

- O uso de $100 \%$ de biodiesel no trator não limita o funcionamento do mesmo, entretanto, aumentou o consumo específico em $26,34 \%$;

- A opacidade da fumaça tem uma redução de $36,04 \%$ quando o trator utilizou biodiesel B100 como combustível;
- Aopacidade da fumaça do motor foi influenciada pelo tipo de biodiesel, sendo melhor resultado para o biodiesel de dendê. Entretanto a opacidade da fumaça reduziu à medida que foi aumentada a proporção de mistura no diesel.

\section{REFERÊNCIAS BIBLIOGRÁFICAS}

ABNT - ASSOCIAÇÃO BRASILEIRA DE NORMAS TÉCNICAS. ABNT 13037: Veículos rodoviários automotores - Gás de escapamento emitido por motor em aceleração livre Determinação da opacidade. Rio de Janeiro: 2001. 
ANDREOLI, I., CENTURION, J.F. Levantamento detalhado dos solos da Faculdade de Ciências Agrárias e Veterinárias de Jaboticabal. In: CONGRESSO BRASILEIRO DE CIÊNCIA DO SOLO, 27, Brasília, 1999. Anais..., Brasília, Sociedade Brasileira de Ciência do solo, 1999. 32p. (T025-3 CD-ROM)

BANZATTO, D.A.; KRONKA, S.N. Experimentação agrícola. $4^{\text {a }}$ ed. Jaboticabal: FUNEP, 2006. 237p.

BELMIRO, T.; FURLAN, J.J.; NODARI, A. Riqueza para a Amazônia, Agroanalysis, São Paulo, v.27, n.7, p.27-28, 2007.

CASTELLANELLI, M.; SOUZA, S.N.M.; SILVA, S.L.; KAILER, E.K. Desempenho de motor ciclo diesel em bancada dinamométrica utilizando misturas diesel/biodiesel. Engenharia Agrícola, Jaboticabal, v.28, n.1, p.145-153, 2008.

\section{CONSELHO NACIONAL DO MEIO AMBIENTE} - CONAMA, RESOLUÇÃO CONAMA no 251, de 7 de janeiro de 1999. Dispõe sobre os critérios, procedimentos e limites máximos de opacidade da emissão de escapamento dos veículos automotores do ciclo diesel, em uso no Território Nacional, a serem utilizados em programas de I/M. Diário Oficial da União, Poder Executivo, Brasília, DF, $\mathrm{n}^{\circ} 7$, de 12 de janeiro de 1999, Seção 1, página 97.

CORRÊA, I.M.; MAZIERO, J.V.G.; ÚNGARO, M.R.; BERNARDI, J.A.; STORINO, M. Desempenho de motor diesel com misturas de biodiesel de óleo de girassol. Ciência e Agrotecnologia, Lavras, v.32, n.3, p.923-928, 2008.

DABDOUB, M.J.; BRONZEL J.L.; RAMPIN, M.A. Biodiesel: visão crítica do status atual e perspectivas na academia e na indústria. Química Nova, v.32, n.3, p.776-792, 2009.

LÔBO, I.P.; FERREIRA, S.L.C.; CRUZ, R.S. Biodiesel: parâmetros de qualidade e métodos analíticos. Química Nova, v.32, n.6, p.15961608, 2009.
LOPES, A. Biodiesel em trator agrícola: desempenho e opacidade. 2006. 158f. Tese (Livre-Docência em Agronomia) - Faculdade de Ciências Agrárias e Veterinárias de Jaboticabal, Universidade Estadual Paulista, Jaboticabal, 2006.

LOPES, A.; CAMARA, F.T.; TABILE, R.A.; SILVA, R.P.; FURLANI, C.E.A.; BARBOSA, A.L.P.B.F. Diesel S500 x Interior: opacidade da fumaça de tratar agrícola- Parte I. In: CONGRESSO BRASILEIRO DE PLANTAS OLEAGINOSAS, ÓLEOS, GORDURAS E BIODIESEL-"BIODIESEL: COMBUSTÍVEL ECOLÓGICO”, 4., 2007, Varginha. Anais... Lavras: UFLA, 2007. p.625-628.

MAZZIERO, J.V.G.; CORRÊA, I.M.; TRIELLI, M.A.; BERNARDI, J.A.; D'AGOSTINI, M.F. Avaliação de emissões poluentes de um motor diesel utilizando biodiesel de girassol como combustível. Engenharia na Agricultura, Viçosa, v.14, n.4, p.287-292, 2006.

MENEGHETTI, S.M.P., MENEGHETTI, M.R., SERRA, T.M., BARBOSA, D.C.; WOLF, C.R. Biodiesel Production from Vegetable Oil Mixtures: Cottonseed, Soybean, and Castor Oils. Energy e Fuels, v.21, n.6, p.3746-3747, 2007.

MURUGESAN, A.; UMARANI, C.; SUBRAMANIAN, R.; NEDUNCHEZHIAN, N. Bio-diesel as an alternative fuel for diesel engines. Renewable and Sustainable Energy Reviews, Uttaranchal, v.3, n.3, p.653-662, 2009.

SORANSO, A.M.; GABRIEL FILHO, A.; LOPES, A.; SOUZA, E.G. De, DABDOUB, M.J.; FURLANI, C.E.A.; CAMRA, F.T. Desempenho dinâmico de um trator agrícola utilizando biodiesel destilado de óleo residual. Revista Brasileira de Engenharia Agrícola e Ambiental, Campina Grande, v.12, n.5, p.553-559, 2008.

TABILE, R.A.; LOPES, A.; DABDOUB, M.J.; CAMARA, F.T.; FURLANI, C.E.A.; SILVA, R.P. Biodiesel de mamona no diesel interior e metropolitano em trator agrícola. Engenharia Agrícola, Jaboticabal, v.29, n.3, setembro 2009. 


\section{TECNOMOTOR. TECNOMOTOR} ELETRÔNICA DO BRASIL. OPACER TM 133 - Opacímetro de amostragem: manual de operação. São Carlos, 2010. 26p.

TEIXEIRA, L.S.G.; COUTO, M.B.; SOUZA, G.S.; ANDADE FILHO, M.; ASSIS, J.C.R.; GUIMARÃES, P.R.B.; PONTES L.A.M.; ALMEIDA, S.Q.; TEIXEIRA, J.S.R.; Characterization of beef tallow biodiesel and their mixtures with soybean biodiesel and mineral diesel fuel. Biomass and Bioenergy, v.34, n.4, p.438441, 2010.

ZUH, L.; ZHANG, W.; LIU, W.; HUANG, Z. Experimental study on particulate and NOx emission of a diesel engine fueled with ultra low sulfur diesel, RME-diesel blends and PME-diesel blends. Science of the Total Environment, v.408, n. 5, p.1050-1058, 2010. 